\title{
Is mare endometrosis linked to oviduct fibrosis?
}

\author{
Pedro Pinto-Bravo 1,2, Maria Rosa Rebordão ${ }^{1,2}$, Ana Amaral', Carina Fernandes ${ }^{1}$, Cristina Cuello ${ }^{3}$, Inmaculada Parrilla ${ }^{3}$, Emilio Mar- \\ tínez ${ }^{3}$, Rosário P. Roberto da Costa ${ }^{2}$, Dariusz J. Skarzynski ${ }^{4}$ and Graça Ferreira-Dias ${ }^{7}$ \\ ${ }^{1}$ CIISA, Faculty of Veterinary Medicine, University of Lisbon, Lisbon, Portugal \\ ${ }^{2}$ Coimbra College of Agriculture, Coimbra, Portugal \\ 3 Faculty of Veterinary, University of Murcia, Murcia, Spain \\ ${ }^{4}$ Institute of Animal Reproduction and Food Research of PAS, Olsztyn, Poland.
}

\begin{abstract}
Summary: Endometrosis is a chronic degenerative disease of the mare's endometrium characterized by the presence of collagen fibers. Besides several causes, such as recurrent endometritis, endometrosis has been highly related to mare aging. Biopsy of mare endometrium has been used either as a diagnostic tool to assess inflammatory and fibrotic changes, or as a prognosis means of reproductive performance. We have evaluated if the presence of mare endometrial fibrosis was related to fibrosis in the oviduct. Collagen type I (COL 1 ) and collagen type III (COL3) fibers were present in mare endometrium and in all portions of the oviduct (infundibulum, ampulla, isthmus), as detected by specific collagen protein staining with picrosirius red (PSR), and by real-time polymerase chain reaction (qPCR). When the oviduct was considered as a whole, a decrease in COL3 mRNA levels was noted in the oldest mares (>17), when compared to the youngest ones. A correlation between oviduct and endometrium fibrosis was examined. The protein COL3 was mostly found in the youngest mares' endometria and oviducts, in contrast to $\mathrm{COL} 1$ detected in older mares with endometrosis. In conclusion, since collagen increased in equine endometrium and oviduct with mares aging, the existence of a possible correlation between fibrosis in the endometrium and oviduct is suggested. To the best of our knowledge this is the first study that relates endometrosis to the presence of fibrosis in the mare oviduct. Thus, the histopathological evaluation of mare endometrium could give additional information on oviduct fibrosis, where a biopsy for diagnostic purposes cannot be performed.
\end{abstract}

Keywords: mare, oviduct, endometrium, fibrosis, endometrosis, collagen, reproduction

Citation: Pinto-Bravo P., Rebordão M. R., Amaral A., Fernandes C., Cuello C., Parrilla I., Martínez E., Roberto da Costa R. P., Skarzynski D. J., Ferreira-Dias G. (2018) Is mare endometrosis linked to oviduct fibrosis? Pferdeheilkunde 34, 43-46; DOI 10.21836/PEM20180107

Correspondence: Graça Ferreira-Dias, Faculdade de Medicina Veterinária, Av. Universidade Técnica, $1300-477$ Lisboa, Portugal; gmlfdias@fmv.ulisboa.pt

\section{Introduction}

Fibrosis is defined by the excessive accumulation of fibrous connective tissue (components of the extracellular matrix (ECM) such as collagen and fibronectin) in and around inflamed or damaged tissue, which can lead to permanent scarring, organ malfunction and, ultimately, death, as seen in end-stage liver disease, kidney disease, idiopathic pulmonary fibrosis (IPF) and heart failure (Wynn 2011).

Despite having distinct etiological and clinical manifestations, most chronic fibrotic disorders have in common a persistent irritant that sustains the production of growth factors, proteolytic enzymes, angiogenic factors and fibrogenic cytokines, which stimulate the deposition of connective tissue components that progressively remodel and destroy normal tissue architecture (Tomasek et al. 2002). When injuries occur, damaged epithelial and/or endothelial cells release inflammatory mediators that initiate an antifibrinolytic-coagulation cascade, which triggers the formation of both blood clots and a provisional extracellular matrix (ECM) (Kumar et al. 2005). Platelets when exposed to ECM will trigger aggregation, clot formation, hemostasis and their degranulation will promote vasodilation and increased blood vessel permeability, while stimulate myofibroblasts (collagen-secreting $\alpha-S M A+$ fibroblasts). Epithelial and/or endothelial injured cells produce metalloproteinases (MMPs), which disrupt cell basement membrane, allowing the efficient recruitment of inflammatory cells to the site of injury. When repeated injury occurs, chronic inflammation and repair cause an excessive accumulation of
ECM components (such as hyaluronic acid, fibronectin, proteoglycans, and interstitial collagens) that will contribute to the formation of a permanent fibrotic scar, mainly by collagen I (COL1) (Wynn 2007). The net amount of collagen deposited by fibroblasts is regulated continuously by collagen synthesis and collagen catabolism. The turnover of collagen and other ECM proteins is controlled by various MMPs and their inhibitors (tissue inhibitors of metalloproteinases - TIMPs), which are produced by granulocytes, macrophages, epidermal cells, and myofibroblasts. Shifts in these opposing mechanisms (synthesis versus catabolism) regulate the net increase or decrease of collagen within a wound (Wynn 2007).

\section{Fibrosis in mare endometrium}

A transient breeding-induced endometritis that occurs soon after breeding is a normal event in the mare (Troedsson 2006). As part of the innate immunity system, neutrophils (PMN) are the first inflammatory cells to defend against the invading microorganisms, by arriving at the infection site and killing bacteria through diverse mechanisms (Brinkmann 2011). As in other tissues, the equine endometrium, when challenged by bacteria or non-infectious stimuli, such as semen, blood PMN migrate across the blood vessel wall and reach the uterus (Zerbe et al. 2004, Katila 2012). At $2 \mathrm{~h}$ and $24 \mathrm{~h}$ after breeding, a larger number of PMN were detected in the uterine lumen in mares more susceptible to endometri- 
tis, and with moderate to severe endometrial fibrosis, than in resistant mares (Woodward et al. 2013). There, besides PMN classical mechanisms of phagocytosis, when in the presence of bacteria causing endometritis in mare in vivo, these inflammatory cells are able to form neutrophils extracellular traps (NETs) (Rebordão et al. 2014). These structures are formed by the DNA and cytoplasm proteins released by PMN in response to infectious/non-infectious stimuli (Brinkmann et al. $2011)$. The entanglement of bacteria suggests that equine NETs might be either a phagocytosis-independent complementary mechanism in fighting some of the bacteria causing endometritis in the mare (Rebordão et al. 2014), or a means to sustain infection in loco (Juneau et al. 2011). Besides the antimicrobial properties of NETs, they may also contribute for tissue damage and fibrogenesis while they persist in the mare endometrium (Rebordão et al. 2014, Rebordão et al. 2017).
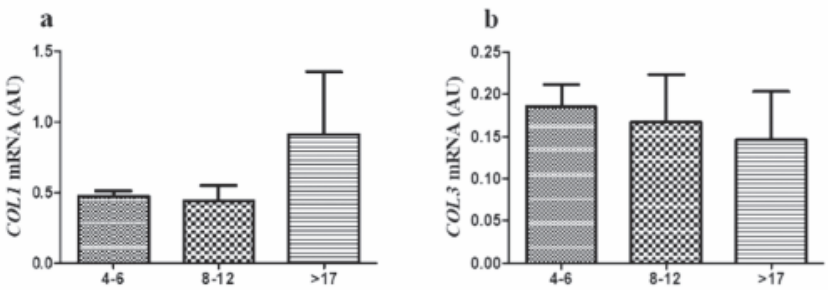

Fig. 1 Transcription of collagen type I (COL1) and III (COL3) genes in endometrium in mares aged between 4 and over 17 years old. Bars represent Mean \pm SD.
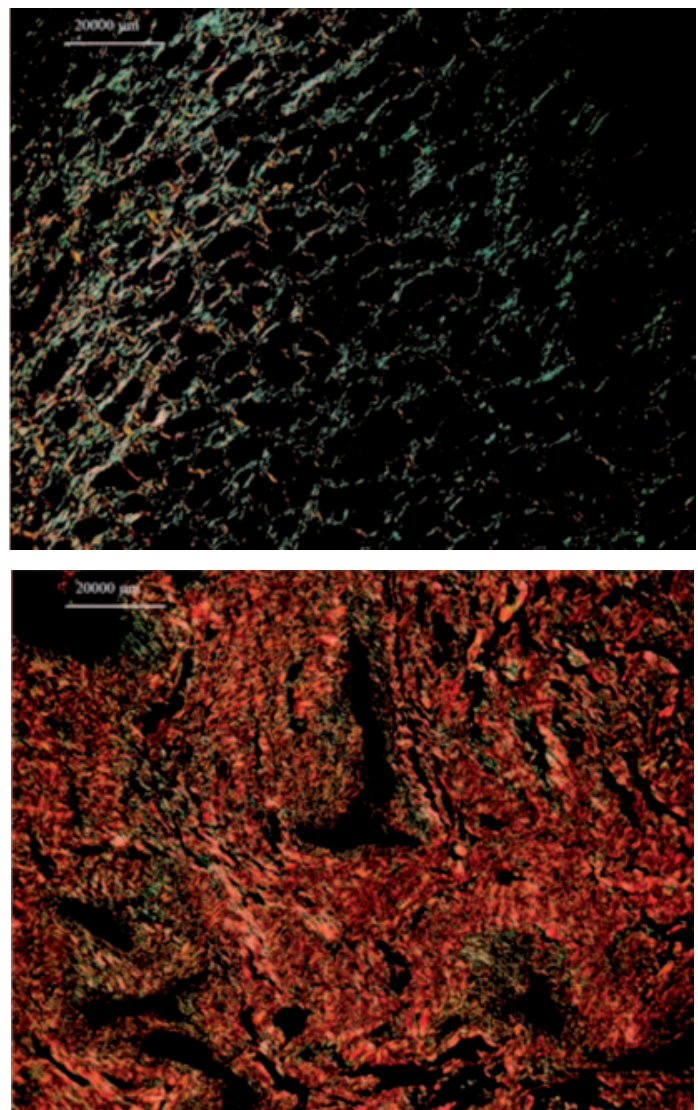

Fig. 2 Mare endometrium stained with picrosirius red and observed and photographed under polarized light microscopy (Leica Leitz DMRD; Mag=100X). On upper panel is depicted a healthy endometrium with mostly COL3 fibres (stained in green), while on the lower panel most collagen fibers are COL1 (stained in red) in severe endometrosis.
Endometrosis, which consists of a severe, progressive and irreversible fibrotic condition in mare endometrium, is major cause of infertility in this species (Kenney 1992, Hoffmann ef al. $2009 \mathrm{a}$ and b). This pathologic process increases in older mares, regardless of parity (Ebert et al. 2014). The cellular mechanisms observed during endometritis in normal mares are comparable to the normal repair mechanisms, known to be altered in fibrosis development in other organs. Tissue repair pathophysiologic tools involving MMPs are likely to be involved in endometrial fibrosis in the mare. An inherent alteration in these mechanisms may play a role in the pathogenesis of this condition, and might arise due to genetic predisposition (Oddsdóttir et al. 2007).

Since in repair and fibrotic processes, COL3 is the first to be expressed, followed by its replacement with COL1 (Bochslerand and Slauson 2002), we have evaluated their gene expression in endometrium of mares from different age groups (Fig. 1), and their protein histochemical expression with picrosirius red (PSR) stain (Fig. 2). No changes either in COL1 or COL3 mRNA levels were noted as mares aged (Fig. 1). Nevertheless, the assessment of the histochemical PSR stained areas, in endometrium previously classified according to Kenney and Doig (1986), showed there was mostly a raise in $\mathrm{COL} 1$ in endometrium with severe endometrosis, with respect to endometria with lighter fibrotic changes and healthy tissue, where COL3 was the most predominant type $(\mathrm{P}<0.05$; Fig. 2).

Previous studies based on PSR staining on mare endometrium suggest that collagen type III fibers are the ones that are synthesized earlier in the development of fibrosis (Masseno 2012, Costa 2015). In addition, COL3 reticular arrangement is mostly found in active endometrosis, while in active or inactive destructive endometrosis COL 1 fibers predominate (Masseno 2012). Once in our work mares with severe endometrosis were included, COL 1 was more widely spread than COL3, in contrast with previous findings on healthier endometrium (Lunelli et al. 2013).

\section{Fibrosis in the Oviduct}

Unlike in most other species, the embryo is maintained within the mare oviduct for a longer period (up to 6 days). This allows a more advanced development, from morula to blastocyst, before arriving into the uterus (Freeman et al. 1991). Therefore, it is extremely important that mares have healthy oviducts to ensure normal early embryo development. Oviduct impairment by fibrosis establishment due to infectious conditions and inflammatory processes, with massive PMN infiltration, induced oviduct cell damage in rat and murine models of salpingitis (Shah et al. 2005, Yang et al. 2015 ).

Since oviduct inflammatory/infectious processes might also lead to infertility in the mare, we aimed at investigating collagen gene expression and deposition in the oviduct with respect to aging and endometrial fibrosis. Thus, based on qPCR and histochemical PSR staining data we have realized that collagen existed in all portions of the oviduct (infundibulum, ampulla, isthmus) and endometrium in all mares age groups, to different extents. When the oviduct was considered as a whole, COL3 mRNA transcripts were higher in the youn- 
gest mares, from 4 to 8 years of age, when compared to the other age groups (10-12; $>17$ years old) ( $P<0.05$; Fig. 3$)$. In addition, when we considered the different anatomical
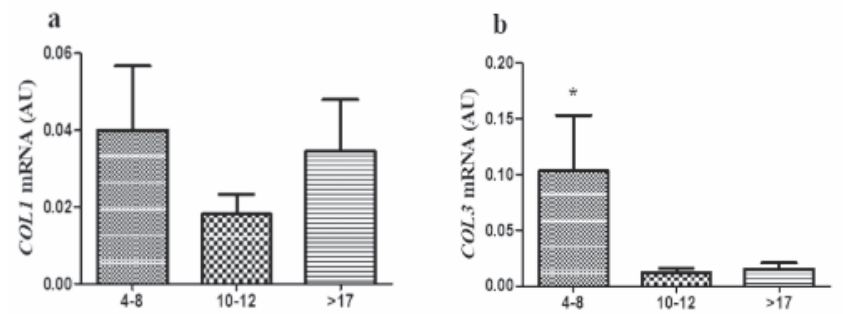

Fig. 3 Transcription of collagen type I (COL1) and III (COL3) genes in the oviduct of mares aged between 4 and over 17 years old. Bars represent Mean \pm SD. ${ }^{*} P<0.05$.
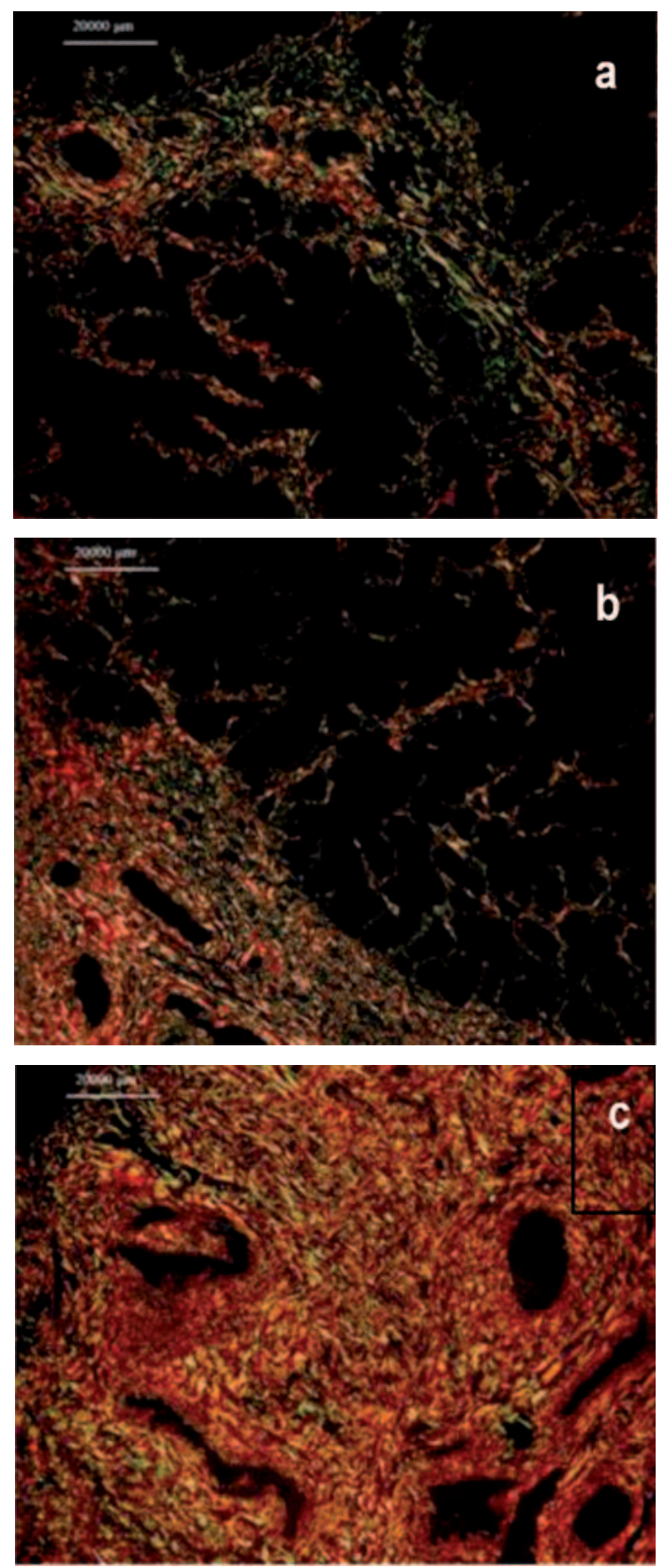

Fig. 4 Mare oviduct ( $a$ - infundibulum; b-ampulla; c - isthmus) stained with picrosirius red and observed and photographed under polarized light microscopy (Leica Leitz DMRD; Mag=100X). COL3 fibers are stained in green, and COLl are stained in red. parts of the oviduct separately (data not shown), this raise in COL3 transcripts in young mares oviduct was mainly ascribed to the infundibulum and isthmus $(P<0.05)$. Nevertheless, when disregarding mares' age, the transcription of $\mathrm{COL} 1$ and COL3 in the infundibulum presented the lowest level with respect to the ampulla and isthmus $(P<0.05)$, which may be related to oviduct anatomical features and function. This predominance of COL3 in young mares\# infundibulum and isthmus is in agreement with COL3 protein area present in healthy mare endometrium and stained by PSR.

The histological PSR staining of COL1 and COL3 protein confirmed the presence of these two types of fibers in the different parts of mare s oviduct. Also, COLl was more expressed than COL3 in all portions of the oviduct (Fig. 4), mainly in the oldest mares $(\mathrm{P}<0.05$; data not shown).

A correlation between oviduct and endometrium fibrosis was examined. Since COL1 and $\mathrm{COL} 3$ increase in equine endometrium and oviduct as the mares age, the existence of a possible correlation between endometrium and oviduct fibrosis may be suggested. To the best of our knowledge this is the first study that relates endometrosis to the putative simultaneous presence of fibrosis in the mare oviduct. Thus, the histopathological evaluation of mare endometrium could give additional information on oviduct fibrosis, where a biopsy for diagnostic purposes cannot be performed.

\section{Funding}

Fundação para a Ciência e Tecnologia, Portugal, (PTDCCVT-REP-4202-2014) and MAESTRO grant (No2011/02/A/ NZ5/00338) from the National Science Center, Poland.

\section{References}

Bochsler P. N., Slauson D. O. (2002) Inflammation and repair of tissue. In: Slauson, D.O. and Cooper, B.J., Eds., Mechanisms of Disease: A Textbook of Comparative General Pathology, 3rd Edition, Mosby, St. Louis, 140-245

Brinkmann V. (2011) Neutrophil extracellular traps in microbial infections. In: Tacchini-Cottier F, Zandbergen G (eds), Neutrophils in Infectious Diseases.Bentham eBooks, Dubai, pp. 3-10

Costa L. D. (2015) Histochemical and immunohistochemical characterization of fibrotic changes in mares endometrosis. Msc Thesis, School of Veterinary Medicine and Animal Science, University of São Paulo, Department of Veterinary Clinic, São Paulo, Brazil

Ebert A., Schoon D., Schoon H-A. (2014) Age-related endometrial alterations in mares- biopsy findings of the last 20 years. In: Rakkwitz R., Pees M., Aschenbach J. R., Gäbel G. (Eds), 7th Leipzig Veterinary Congress, 8th International Conference on Equine Reproductive Medicine. Lehmanns Media GmbH, Berlin, Germany, January 2014. pp 230-232

Freeman D. A., Weber J. A., Geary R.T., Woods G. L. (1991) Time of embryo transport through the mare oviduct. Theriogenology 36, 823-830

Hoffmann C., Bazer F. W., Klug J., Aupperle H., Ellenberger C., Schoon H. A. (2009a) Immunoh istochemical and histochemical identification of proteins and carbohydrates in the equine endometrium Expression patterns for mares suffering from endometrosis. Theriogenology 71, 264-274

Hoffmann C., Ellenberger C., Mattos R. C., Aupperle H., Dhein S., Stief B., Schoon H. A. (2009b) The equine endometrosis: new insights into the pathogenesis. Anim. Reprod. Sci.111, 261-278

Juneau R. A., Pang B., Weimer K. E. D., Armbruster C. E., Swords 
W. E. (2011) Nontypeable haemophilus influenza initiates formation of neutrophil extracelular traps. Infect. Immun. 79, 431-438

Katila T. ( 2012) Post-mating inflammatory responses of the uterus. Reprod. Dom. Anim. 47 (Suppl. 5), 31-41

Kenney R. M. (1992) The aetiology, diagnosis, and classification of chronic degenerative endometritis. In: Hughes JP. (ed.), Workshop on Equine Endometritis. Equine Vet. J. Newmarket 125, p. 186

Kenney R. M., Doig P. A. (1986) Equine Endometrial Biopsy. In: Current Therapy in Theriogenology: Diagnosis, Treatment, and Prevention of Reproductive Diseases in Small and Large Animals. WB Saunders Philadelphia, Pennsylvania, USA. pp. 723-729.

Kumar V, Abbas A. K., Fausto N. (2005) Tissue renewal and repair: regeneration, healing, and fibrosis. In: Pathologic basis of disease. V. Kumar, A.K. Abbas, \& N. Fausto (Editors). Elsevier Saunders. Philadelphia, Pennsylvania, USA. pp. 87-118

Yang J, Chi C, Liu Z, Yang G, Shen Z-J, Yang X-J. (2015) Ultrastructure damage of oviduct telocytes in rat model of acute salpingitis. J. Cell. Mol. Med. 19, 1720-1728

Lunelli D, Cirio S, Leite S, Camargo C, Kozicki L. (2013) Collagen types in relation to expression of estradiol and progesterone receptors in equine endometrial fibrosis. Adv. Biosci. Biotechnol. 4, 599-605

Masseno A. P. B. (2012) Assessment of endometrial fibrosis and myofibroblasts in endometrosis active and inactive mares. $\mathrm{PhD}$ Thesis, School of Veterinary Medicine and Animal Science, University of São Paulo, Department of Veterinary Clinic, São Paulo, Brazil.

Oddsdóttir C. (2007) Development of endometrial fibrosis in the mare: Factors involved in tissue remodelling and collagen deposition. Doctoral Thesis. The University of Edinburgh, UK.

Pardo A, Selman M. (2006) Matrix metalloproteases in aberrant fibrotic tissue remodeling. Proc. Am. Thorac. Soc. 3, 383-388
Rebordão M. R., Carneiro C., Alexandre-Pires G., Brito P., Pereira C., Nunes T., Leitão A., Vilela C., Ferreira-Dias G. (2014) Neutrophil extracellular traps formation by bacteria causing endometritis in the mare. J. Reprod. Immunol.106, 41-49

Rebordão M. R., Amaral A., Lukasik K., Szóstek A. Z., Galvão A., Pinto Bravo P., Skarzynski D. J., Ferreira-Dias G. (2017) Enhanced collagen formation in mare endometrium by neutrophils extracellular traps proteins. Proceedings of 14th Congreso Internacional Reprodución Animal (AERA) 9-11 Nov. 2017. Barcelona, Spain, in press

Shah A. A., Schripsema J. H., Imtiaz M. T., Sigar I. M., Kasimos J., Matos P. J., Inouye S., Ramsey K. H. (2005) Histopathologic changes related to fibrotic oviduct occlusion after genital tract infection of mice with Chlamydia muridarum. Sex. Transm. Dis. 32, 49-56

Tomasek J. J., Gabbiani G., Hinz B., Chaponnier C., Brown R. A. (2002) Myofibroblasts and mechanoregulation of connective tissue remodelling. Nat. Rev. Mol. Cell Biol. 3,349-363

Troedsson M. H. ( 2006) Breeding-induced endometritis in mares. Vet. Clin. North Am. Equine Pract. 22, 705-712

Woodward E. M., Christoffersen M., Campos J., Betancourt A., Horohov D., Scoggin K. E., Squires E. L., Troedsson M. H. T. (2013) Endometrial inflammatory markers of the early immune response in mares susceptible or resistant to persistent breeding induced endometritis (PBIE). Reproduction 145, 289-296

Wynn T. A. (2007) Common and unique mechanisms regulate fibrosis in various fibroproliferative diseases. J. Clin. Invest. 117, 524 529

Wynn T. A. (2011) Integrating mechanisms of pulmonary fibrosis. J. Exp. Med. 208, 1339-1350

Zerbe H., Engelke F., Klug E., Schoon H. A., Leibold W. (2004) Degenerative endometrial changes do not change the functional capacity of immigrating uterine neutrophils in mares. Reprod. Dom. Anim. 39, 94-98 